\title{
A nação na ponta da meia-língua: ausência, silêncio e morte em A menina morta
}

Maria Ângela de Araújo Resende I UFSJ

Resumo: A partir da leitura da obra A menina morta, de Cornélio Penna, publicada em 1954, pretende-se discutir as tentativas de representar a nação pela via do feminino. Considerando-se a voz, elemento essencial para a efetivação das narrativas da nação, a "meia-lingua", configurada na obra, evoca as vozes despossuidas das personagens femininas: as escravas, a governanta alemã, as parentas agregadas, o fantasma da menina morta e Carlota, a filha recém-chegada da corte, que daria continuidade a um projeto fundador. Na contra-mão da convivência pacífica entre casa-grande e senzala, pontuada por Gilberto Freyre, A menina morta representa um tipo de narrativa que pode indicar a inviabilidade de um projeto fundador.

Palavras-chave: nação, fundação, memória, voz, lingua.

\section{Introdução}

Em 1976, Luiz Costa Lima publica A perversão do trapezista-o romance de Cornélio Penna, no qual dá ênfase à obra $A$ menina morta e deixa claro, na Introdução, a necessidade de falar a partir de uma posição teórica 
que, segundo ele, não se resume em "estrutural, neo-estrutural ou o que seja" (op. cit., p.11). Entretanto, considerando-se a natureza do método, e mesmo alertando para o perigo dos rótulos, Costa Lima se vale do binarismo como um dos procedimentos de análise, partindo dos modos de representação do masculino e do feminino e suas trocas simbólicas nos espaços onde se desenvolve a trama. Para isto, contrapõe ao Grotão - incluindo a fazenda autárquica, os campos cultivados e a floresta que a cerca - a Corte, urbana e europeizada, traçando um desenho espacial marcado pela dicotomia entre os caminhos que partem da casagrande. Um deles, o caminho da Corte, signo do caminho do masculino, se constitui através das personagens: o Comendador, o Barão, um dos filhos dos senhores, que, após um breve retorno, abandona o Grotão e passa a viver definitivamente na Corte.

O outro, o caminho da clareira, metaforizando o caminho do feminino nas figuras de Mariana, a menina morta e Carlota. Se levarmos em conta essa relação, poderíamos nos valer de um plano histórico e de um plano mítico que irão dar sustentação, em parte, à proposição do autor, uma vez que ele estabelece um sistema de oposições entre natureza e cultura. O espaço da mata também funciona como contraponto ao espaço da fazenda e de seus moradores, também eles divididos, hierarquicamente: o Senhor e a Senhora, as parentas agregadas (D. Virgínia., D. Inacinha, Sinhá Rola e Celestina) o administrador português, a governanta alemã, os escravos de dentro e os escravos de fora, e são elementos importantes para identificarmos a passagem do real ao simbólico e dos fantasmas expressos nas formas de interdição.

Pretendendo localizar, historicamente, a matéria narrada, que chamará de "tempo real", Costa Lima destaca os referentes espaciais e temporais presentes no romance - o Rio Paraíba, os trilhos de ferro ao pé da serra, mais tarde a Estrada de Ferro Mauá e a Vila de Porto Novo - de tal maneira que, fazendo as devidas aproximações históricas, demarca o desenvolvimento da ação entre os anos de 1867 e 1871, portanto, anos antes da abolição da escravatura e período da agricultura cafeeira.

Os fantasmas e as formas de interdição são bem desenvolvidos por Miranda (1997), ao destacar questões fundamentais no romance de Cornélio Pena: o silêncio e a linguagem em dobras, a morte como signo disseminador de sentidos, o histrionismo e a loucura, o ritual da devoração que inclui três vítimas expiatórias: a menina, Florêncio e Carlota, o casamento, que seria o signo de vida e continuidade, tanto para Carlota como para o 
Grotão, revelado como signo de morte para ela e a fazenda. O autor abre caminhos para pensarmos o resgate da herança do passado, onde se localizaria o processo de formação de nossa nacionalidade, que o período escravocrata traduz sob a forma de violento dissenso. Diz ele:

(...) Cornélio Penna não só estaria problematizando a pretensa unidade que nos constituiria enquanto nação, mas assinalando a permanência de um conflito não sanado na origem e que, sob a forma de um fantasma desagregador, continua a nos assombrar e a nos manter exilados no passado, como num pesadelo que não parece ter fim. (MIRANDA, 1977, p. 482).

Assim, parece-nos pertinente discutir e ampliar algumas questões levantadas por Costa Lima quanto à relação natureza e cultura, que vise uma linha interpretativa da seguinte ordem: privilegiar aspectos da narrativa que expressem o desejo de fundação da nação e sua representação, tentando conciliá-los com as questões levantadas por Melo Miranda, ou seja, a herança do passado como (im)possibilidade de formar a nação. Afinal, qual (ais) seria(m) o fantasma(s) desagregador (es) que permeiam as dobras e os silêncios deste texto?

\section{Em busca da nação}

Ao lançar A menina morta aos leitores brasileiros em 1954, poderia se pensar que Cornélio Penna estaria na contramão do processo modernizador pelo qual o Brasil passava, ao colocar em cena uma obra que, entre outros temas, também falasse da escravidão. Considerando-se o a onda desenvolvimentista dos anos 50, o momento anunciava o desejo de uma identidade que se pautasse na modernidade e no progresso. Seria, então, possível, buscar uma origem que traduzisse o desejo de pátria, já que o autor de Fronteira construiu um texto privilegiando a subtração na origem, da qual Homi Bhabha (1998, p. 225) nos fala, cunhando personagens desterritoralizadas, que, através de sua "meia-língua" metaforizam as margens e o despaisamento e cujas identidades não podem ser compartilhadas? Qual seria o discurso que daria corpo e voz à nação imaginada, uma vez que a narrativa se constrói mais pelas "reticências e cochichos incompreensiveis" (p.37), pelas "cogitações estéreis dos moradores do Grotão" (p. 155) e por "palavras balbuciadas" (p.199)? Reticências e lacunas que atravessam o 
sussurro dos escravos, as histórias contadas pelas negras, interrompidas pelo medo e sobressalto, os balbucios e murmúrios das parentas pobres e agregadas, sempre se esgueirando pelos quartos e corredores, o silêncio/presença perturbadora da menina-morta e a quase incomunicabilidade dos senhores, materializada nas figuras de Mariana e do Comendador.

Além disso, a voz que conduz o texto pertence a um narrador atento aos detalhes, à extrema hierarquização e à ritualização da vida cotidiana na fazenda, mas cuja precisão microscópica é traída pela indefinição produzida pelos jogos de luz e sombra, o que evidencia um tipo de saber "não sabendo". Em outras palavras, esse narrador estaria mais na direção de um não-saber, tragado pela indecibilidade de sua também "meia-língua", pois nem o leitor nem as personagens encontram respostas para os fatos acontecidos, envolvidos por um passado de neblinas: “... não vamos porque não sabemos de nada, nem procuramos saber" (p. 216) "- Ninguém me diz nada nesta casa! E não compreendo o que dizem..." (p. 238).

Se, por um lado, o narrador é capaz de chegar ao saber e à lembrança quase exata da letra em alto relevo gravada numa caixa, dos dísticos bordados nas cambraias de linho ou do "... balde de porcelana verde com medalhões onde se viam castelos medievais...” (p. 210), por outro não oferece a chave de um mistério indecifrável e interdito. A linguagem narrativa, aparentemente lenta e sinuosa, marcada pelo signo das minúcias e pelo esforço metonímico, encobre o silêncio e a falta que atravessam as personagens.

O narrador faz falar os objetos, atentando para o detalhamento da casa-grande e seus amplos espaços interno e externo, telhados e janelas, corredores, móveis duros e severos, cofres, escrínios e candelabros, armários e gavetas, roupas, leques e xales, caixinhas de música, cozinha e despensa, as comidas, seus cheiros e sabores, latas de biscoito, os objetos provenientes da "Velha Europa e da Índia". Narrando a ritualização e a organização da vida cotidiana, revela os hábitos dos moradores da fazenda e sua disposição à mesa, nos horários das refeições. A descrição da oração diária revela a hierarquia imposta àquela comunidade, todos dispostos de acordo com sua importância no complexo patriarcal: senhores, parentes agregados, governanta, administrador, feitores, médico da enfermaria e médico do Partido, mucamas, mulatinhas de dentro, escravos na senzala e escravos nas plantações. Entretanto, "aquele enorme organismo... movido com a regularidade dos cronômetros"(p. 225) encobre ressentimentos e hostilidades e revela silêncios 
e rasuras. Se existe uma língua pedagógica que faz falar os objetos, o territórios e os hábitos daquela comunidade que, de certa maneira, poderiam servir de mote para a questão identitária, essa mesma língua é suplantada pelo não-dito, pelo mistério e terror que potencializam a violência do não-saber sobre um passado insepulto, sepultamento análogo ao mistério que permeia a morte da menina e de Florêncio e o desaparecimento súbito de Mariana. O narrador, ao se referir à hesitação das escravas, com sua meia-língua: "a mais velha delas (...) dizia com voz sibilante e atropelava as palavras em estranha algaraviada de palavras africanas $e$ portuguesas" (p.78) experimenta, também, a hesitação como marca textual, portanto, contrária à forma totalizadora e totalizante de se pensar a fundação. Ao presidir o réquiem deste corpo-texto vivo, morto-vivo, em aflição, cheio de dúvidas, vagando entre vultos e sombras, luz e trevas, testemunha a desconstrução, a desagregação e a ruína do mundo patriarcal - "a melancolia do nosso patriarcalismo", de acordo com Costa Lima (op.cit.), portanto, a falência de um projeto fundador.

Por que falência? A perspectiva do plebiscito diário pareceria viável, se as fronteiras internas estabelecidas nesse mundo patriarcal pudessem propiciar espaços de identidades a serem compartilhadas e negociadas. Entretanto, o que se verifica é a negação de uma possível unidade social, marcada por hostilidades, ressentimentos e ódios que permeiam as personagens, que se movem e convivem naquele organismo, movidos pelo medo e pela imposição.

Lembrar para esquecer? Estaria esse esquecer na direção do "estranho esquecimento" da história do passado da nação que envolve a violência envolvida no estabelecimento dos seus escritos, conforme postula Ernest Renan (2000), apontando para a compreensão de um passado que possa indicar a construção do presente e do futuro? O que se observa é a configuração de um mundo espectral, onde os vultos e sombras sugeridos também formam os fantasmas passados que impedem o saber de Carlota. Através de Carlota, poderia o narrador suscitar-nos a seguinte pergunta: o que fizeram do nosso passado?

\section{Em busca da voz}

Um ponto que serve de baliza para a minha leitura é a "radicalidade com que o romancista se entregava à tarefa de fazer falar o que não tem voz e que, a custo, emergia como alteridade constitutiva de sua escrita" (Miranda,1997, p. 472). Duas coordenadas aqui se inscrevem: 1) a fala dos que não têm voz metaforizada na meia-língua do estrangeiro (Frau Luiza, o 
administrador português) do negro, dos serviçais e das parentas "que deviam viver como sombras", funcionando como um certo tipo de exílio: "Tudo lhe parecia inimigo e hostil nessa fazenda tão grande onde a tratavam como estrangeira" (p.109); 2) como essa alteridade é representada pelo texto, uma vez que a matéria narrada em detalhes e com vigor descritivo evidencia um narrador escorregadio, hesitante e também irônico, a ironia aqui tomada, principalmente, pela visão desconstrutora do mundo patriarcal. O dissenso do qual fala Melo Miranda ratifica, então, a quebra de uma representação homogênea da pátria, uma vez que Cornélio Penna, ao se valer do período escravocrata para uma possível interpretação da nação, põe em xeque as formulações de Gilberto Freyre quando o sociólogo apresenta a convivência quase pacífica entre casa-grande e senzala e o intercâmbio étnico para explicar a formação da identidade nacional.

No ensaio O fado tropical de Gilberto Freyre, Stélio Marras (2000), assinala que o ponto focal que norteia a obra freyriana quanto às relações entre casa-grande e senzala, "raiz do complexo patriarcal", origina suas marcadas impressões reconhecendo a virtude da empresa colonial portuguesa e grafando de otimismo a experiência da mestiçagem, "esta que fundou a maior civilização moderna nos trópicos". (CG\&S). O que se verifica em A menina morta é uma permanente tensão e conflito entre os membros da comunidade patriarcal: os moradores da casa-grande não se entendem, as parentas agregadas disputam pequenos restos de consideração dos senhores: “-... Acho que só nos duas nos alegramos realmente com a chegada de Carlota. Essas duas acreditam estar em campo de batalha..." (p. 207); as escravas, esquecendose de sua condição de "des-lugar", brigam entre si por reconhecimentos que não existem; os serviçais estrangeiros, nostálgicos da terra natal, tentam encontrar o seu locus, perdidos “... em certo rincão selvagem em plena América, nesse mundo ainda na infância" (p.194) e Florêncio, o escravo mestiço, aparece misteriosamente enforcado, desconstruindo a experiência otimista da mestiçagem. Longe de nos esquecermos do entendimento da nação como narração, creio ser possível creditar A menina morta na fatura de obras que buscaram interpretar o Brasil, a partir de uma interpretação fragmentária e de uma voz não totalizadora. Desta forma, a voz do narrador que preside essa narração do passado, é hesitante e escorregadia, quando, através de seus personagens, pretende encontrar respostas que justifiquem a formação de uma idéia de nação diluída nas lacunas e esquecimentos compulsórios do período escravocrata, marcados pela linhagem do confinamento, da lei patriarcal e da interdição. 
A lei patriarcal, configurada no poder do Senhor, proprietário do Grotão, pai da menina morta e de Carlota, é desestabilizada por uma outra lei que se instaura a partir do retorno de Carlota ao Grotão. Legitimada como herdeira, prometida em casamento para dar continuidade, a personagem recusa o papel que lhe é destinado, busca respostas sobre sua origem e sobre o desaparecimento súbito da mãe.

\section{No fim, o silêncio}

Carlota desterrada e exilada do seu passado e presente. A busca de um ponto de pertencimento é materializada na busca de si mesma e de suas origens. Indagações sobre retratos, cartas, marcas materiais e testemunhas do vivido. Carlota metaforiza, então, a impossibilidade da constituição da nação pelas vias do sacrifício e do dissenso. Na contramão de Gilberto Freyre, que postula a pátria a partir da unidade da família, Menina Morta representa um projeto falido de uma nação encenada sob um jogo de máscaras.

E assim tudo continuava em sua aparência habitual, mas havia um princípio de desagregação, de ruína e desmoronamento que todos suspeitavam, e olhavam para o dono da casa como o único capaz de salvá-los, de tornar fazer reviver e galvanizar aquele grande corpo que lhes parecia agonizante, agitado pelo trabalho subterrâneo da morte. (p. 81)

Se a menina morta, promessa do futuro, é um projeto sequer iniciado por sua morte prematura, Carlota, seu duplo, com passagem pela corte europeizada, também rejeita a sua condição de redimir o Grotão. Recusa-se ao casamento encomendado por seu pai que, se consumado, faria assentar sobre ela o fardo de uma longa e penosa linhagem. Liberta-se das tias-primas que partem e dos escravos a quem concede alforria. Decide ficar só com a mãe, que retorna louca. O seu não saber, apesar de apontar para a morte e a loucura, revela um outro lado da moeda. É a única pessoa que consegue manter-se viva, porque liberta de todo o jugo de sua história: "O Grotão é demasiadamente grande para mim e me tortura pelo peso de seu futuro tão cruel e estranho" (p. 524). 
Disponivel em: bttp://www.letras.ufmg.br/poslit

Abstract: Starting from Cornélio Penna's novel entitled A menina morta, published in 1954, this article discusses the attempts to represent nation by the feminine. Considering that voice is an essential element for the effective building of narratives of the nation, the "balf-language" that figures in the text reverberates the voices of the dispossessed female characters: the slaves, the German governess, the relatives, the dead girl's ghost and Carlota, the daughter recently arrived in court who is assigned to continue the foundation project. Contrary to Gilberto Freyre's idea of a peaceful relationship between casa-grande (the lord's house) and the senzala (the slaves' house), A menina morta represents a kind of narrative that points to the impossibility of a founding project for the nation.

Key words: nation, foundation, memory, voice, language.

\section{Referências Bibliográficas}

ANDERSON, Benedict. Imagined comunities. London: Routledge, 1999.

BHABHA, Homi K. Locais da cultura. DissemiNação. In: O local da cultura. Trad. Myriam Ávila; Eliana Lourenço de Lima Reis e Gláucia Renate Gonçalves. Belo Horizonte: Editora UFMG, 1998.

Bíblia Sagrada. 45 ed. Petrópolis: Ed. Vozes, 2001.

CHAUÍ, Marilena. Brasil-mito fundadore sociedade autoritária. São Paulo: Editora Fundação Perseu Abramo, 2000.

CHEVALIER, Jean \& GHEERBRANT, Alain. Dicionário de símbolos. Trad. Vera da Costa e Silva ...[et al.] 8. ed. Rio de Janeiro: José Olympio, 1994.

FARIA, Marcos Ribas de. A consagração da palavra. In: JB/IDÉIAS, 06/04/2002, p. 8.

KETTENMANN, Andrea. Kablo-Dor e paixão. Trad. Sandra Oliveira. Lisboa: Taschen, 2001.

FREYRE, Gilberto. Casa Grande E Senzala. 17 ed. Rio de Janeiro: José Olympio, 1975.

LIMA, Luiz Costa. A perversão do trapezista.O romance em Cornélio Penna. Rio de Janeiro: Imago Editora Ltda., 1976.

MIRANDA, Wander Melo. A poesia do reesvaziado: imagens de nação no memorialismo mineiro. In: Cadernos da Escola do Legislativo. Belo Horizonte, v. 2, n. 4, p. 95-113, jul./ dez. 1995. 1994.

. Memória e nação. In: Literatura e diferença. IV Congresso Abralic. Anais. São Paulo,

Posfácio. In: PENNA, Cornélio. A menina morta. Rio de Janeiro: Artium, 1997.

PENNA, Cornélio. A menina morta. São Paulo: Artium, 1997.

RENAN, Ernest. ¿Qué es una nación; In: La invención de la nación. Lecturas de la identidad de Herder a Homi Bhabha. Buenos Aires: Ediciones Manantial, 2000, p. 53-66. 